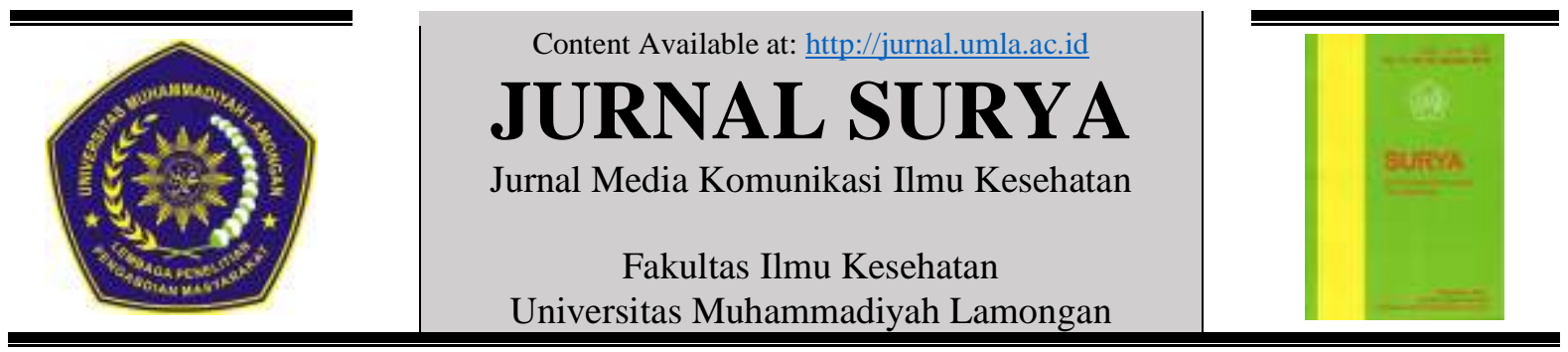

\title{
Pendidikan Kesehatan Menggunakan Metode Video untuk Meningkatkan Pengetahuan Caregiver dalam Merawat Klien Halusinasi
}

Bambang Eryanto

Keperawatan STIKes Indramayu Jawa Barat

\section{ARTIKEL INFO}

\section{Article History:}

\section{Kata Kunci:}

Caregiver

Halusinasi

Metode Video

Pengetahuan

\begin{abstract}
ABSTRAK
Background: Upaya untuk meningkatkan pengetahuan caregiver tentang halusinasi adalah dengan pemberian pendidikan kesehatan jiwa pada caregiver. Peningkatan pengetahuan tersebut dapat dilakukan dengan berbagai metode, diantaranya dengan menonton video.

Objectives: Penelitian ini bertujuan untuk mengetahui efektifitas pemberian pendidikan kesehatan jiwa dengan metode menonton video dalam meningkatkan pengetahuan caregiver tentang halusinasi

Design: Penelitian ini menggunakan eksperimental semu dengan rancangan pre test dan post test group design, dengan sampel 30 responden. Tekhnik pengambilan sampel yang digunakan adalah total sampling, skor pengetahuan caregiver di ukur dengan kuesioner pengetahuan tentang halusinasi yang dikembangkan sendiri dengan uji validitas $(0,707)$ dan uji reliabilitas $(0,968)$. Data yang diperoleh di uji dengan menggunakan uji Wilcoxon test.

Results: Hasil rata-rata pengetahuan pre test caregiver adalah 7,57 naik menjadi 11,80 setelah dilakukan post test. Hasil analisis menggunakan uji wilcoxon didapatkan nilai p-value $0,000<0,05$, artinya ada perbedaan signifikan antara pengetahuan pre test caregiver dengan pengetahuan post test caregiver.

Conclusions: Kesimpulan dari penelitian ini adalah pemberian pendidikan kesehatan menggunakan metode video efektif dalam meningkatkan pengetahuan caregiver, sehingga video ini bisa digunakan untuk pendidikan kesehatan jiwa.
\end{abstract}




\section{PENDAHULUAN}

Masalah gangguan jiwa merupakan masalah kesehatan yang harus segera ditangani secara serius, terutama di lingkungan masyarakat yang masih awam dengan masalah gangguan jiwa dan mempunyai pendapatan perekonomian yang masih rendah. Maramis (2014) mengemukakan bahwa hubungan sosial dan masalah ekonomi yang memburuk dan beban kerja yang tinggi bisa menjadi beberapa pemicu gangguan jiwa. Gangguan jiwa diartikan sebagai keadaan jiwa yang tidak berhubungan dengan realitas (Stuart, 2016). Data World Health Organization (WHO) pada tahun 2016 didapatkan data sebanyak dua puluh satu juta orang di dunia terkena gangguan jiwa skizofrenia dan memerlukan penanganan yang segera untuk dicarikan solusi permasalahan ini oleh para pakar kesehatan jiwa khususnya (Kemenkes RI, 2016).

Di Indonesia, hasil Riset Kesehatan Dasar (Riskesdas) tahun 2013 menunjukkan bahwa prevalensi gangguan jiwa berat adalah 1,7 per 1.000 penduduk. Dari klien gangguan jiwa tersebut $14,3 \%$ atau sekitar 57.000 orang pernah atau sedang dipasung. Angka pemasungan di pedesaan adalah sebesar 18,2 $\%$. Angka ini lebih tinggi jika dibandingkan dengan angka di perkotaan yaitu, sebesar $10,7 \%$. Dapat disimpulkan pemasungan lebih banyak terjadi di pedesaan (Mboi, 2016).

Penderita gangguan jiwa ringan hingga berat di Jawa Barat saat ini mencapai 465.975 orang. Jumlah ini naik secara signifikan dari tahun 2012 yang jumlahnya 296.943. Hal ini mengindikasikan bahwa pengidap gangguan jiwa di Jawa Barat naik sekitar $63 \%$. Tren penderita gangguan jiwa ini diperkirakan akan terus meningkat tiap tahunnya (Purnama, 2013).

Skizofrenia merupakan salah satu gangguan jiwa yang dikategorikan dalam gangguan psikis yang paling serius karena dapat menyebabkan penurunan fungsi manusia dalam melaksanakan aktivitas kehidupan sehari-hari (Jaste \& Mueser, 2008). Gangguan jiwa adalah penyakit otak neurobiologis kompleks yang mempengaruhi kemampuan seseorang untuk memahami dan memproses informasi (Stuart, 2016). Klien skizofrenia juga mengalami penurunan kemandirian dalam perawatan diri, fungsi sosial, sehingga membutuhkan bantuan keluarga (Kartikasari, 2017).

Stuart \& Laraia (2005) menyatakan bahwa klien dengan skizofrenia sebanyak $20 \%$ mengalami halusinasi pendengaran dan penglihatan secara bersamaan, $70 \%$ mengalami halusinasi pendengaran, $20 \%$ mengalami halusinasi penglihatan, dan $10 \%$ mengalami halusinasi lainnya. Berdasarkan data tersebut diketahui bahwa jenis halusinasi yang paling banyak di derita oleh klien skizofrenia adalah halusinasi pendengaran. Pada klien skizofrenia halusinasi sekitar lebih dari $60 \%$ paling dominan yang mempengaruhinya (Suryani, 2013).

Sulistiowati (2010) mengemukakan bahwa peran serta anggota keluarga dalam penanganan klien halusinasi menjadi penting, dimana klien halusinasi memulai hubungan interpersonal pertama di dalam lingkungannya adalah keluarganya itu sendiri. Diharapkan keluarga dapat membantu klien halusinasi dalam belajar mengembangkan nilai, keyakinan, sikap serta perilaku klien, sehingga klien nantinya siap berperan di dalam masyarakat pasca hospitalisasi.

Suryani (2013) mengemukakan bahwa gangguan jiwa merupakan sebuah journey of challenge atau perjalanan yang penuh tantangan. Klien sulit untuk langsung sembuh dan butuh proses waktu yang panjang dalam penyembuhannya. Sehingga butuh pendampingan yang terus menerus dari caregiver sampai klien benar-benar mandiri.

Caregiver adalah seorang individu yang secara umum merawat dan mendukung klien halusinasi dalam menjalankan aktivitasnya sehari-hari yang mempunyai waktu banyak digunakan untuk berinteraksi dengan klien halusinasi (Awad \& Voruganti, 2008). Ketika klien berada di rumah dukungan dari caregiver, keluarga dan lingkungan sekitar pun sangat dibutuhkan agar klien bisa menjalani proses recovery atau penyembuhannya.

Metkono (2014) mengemukakan bahwa dalam merawat anggota keluarga dengan halusinasi dapat menimbulkan beban bagi caregiver. Beban tersebut dapat berupa beban objektif dan beban subjektif. Beban tersebut yang dimiliki caregiver dapat menurunkan kemampuan caregiver dalam merawat klien. Kondisi klien yang relaps 
akan mempertinggi beban yang dirasakan. Ketidakmampuan caregiver dalam merawat dapat menimbulkan perilaku yang buruk. Hal ini disebabkan oleh pengetahuan caregiver yang kurang dalam merawat klien di rumahnya.

Gangguan kesehatan yang diderita salah satu anggota keluarga dapat menimbulkan stres bagi anggota keluarga lain, khususnya caregiver utama. Untuk itu, caregiver perlu menguasai coping skills untuk mengatasi beban yang dialami dalam menjalankan perannya. Diantara berbagai aspek yang berperan untuk tercapainya suatu koping yang efektif bagi caregiver adalah diperlukan pengetahuan dan informasi yang baik dan benar. Artinya, caregiver skizofrenia perlu mempunyai informasi yang cukup mengenai gangguan skizofrenia itu sendiri serta mengetahui beban apa saja yang ditanggung keluarga penderita serta bagaimana cara mengatasinya (Jusuf, 2014). Diharapkan dengan pengetahuan caregiver yang cukup, bisa dijadikan landasan awal terbentuknya perubahan sikap dan prilaku dari caregiver itu sendiri dalam merawat klien halusinasi (Sunaryo, 2004).

Upaya untuk meningkatkan pengetahuan caregiver dalam merawat klien halusinasi adalah dengan pemberian pendidikan kesehatan pada caregiver itu sendiri, sehingga ada perubahan signifikan dalam pengetahuan, sikap maupun keterampilan caregiver dalam merawat klien halusinasi di rumah. Pendidikan kesehatan merupakan pengalaman pembelajaran seseorang dan rencana tindakan apa saja yang akan dilakukan untuk merawat dirinya sendiri secara individu maupun secara bersama-sama, atau berperan sebagai pengambil keputusan untuk merawat kesehatan orang lain dan lingkungannya (Keliat, 2002). Penelitian Farkhah (2017) kualitas hidup caregiver merupakan faktor yang paling dominan terhadap kesembuhan klien skizofrenia.

Penelitian mengenai efektifitas metode untuk meningkatkan pengetahuan keluarga telah dilakukan pada caregiver klien dengan berbagai penyakit. Penelitian yang dilakukan pada 350 wanita dewasa di Odogbolu (yang dilakukan intervensi) dan Ikenne (sebagai kontrol) pada daerah Ogun Nigeria, menunjukkan bahwa pendidikan kesehatan dengan menggunakan media film efektif dalam menciptakan kesadaran dan meningkatkan pengetahuan dan persepsi wanita dewasa tentang kanker serviks dan skrining (Abiodun, 2014). Menurut Arsyad (2007) menjelaskan bahwa video film merupakan salah satu media untuk tujuan pendidikan. Pemutaran video dapat menggambarkan objek atau suatu proses secara tepat, mengajarkan ketrampilan yang dapat disajikan secara berulang-ulang.

Penelitian ini dilakukan di Puskesmas Jatibarang, karena di Puskesmas ini paling tinggi kasusnya di wilayah Indramayu. Berdasarkan rekap data kasus jiwa komunitas di Indramayu terdapat 236 kasus gangguan jiwa di Puskesmas Jatibarang (Dinkes Kabupaten Indramayu, 2014). Puskesmas Jatibarang pernah satu kali melakukan pendidikan kesehatan jiwa dengan metode ceramah pada tahun 2014, namun dalam evaluasinya menunjukkan belum banyak membantu caregiver dalam meningkatkan pengetahuan dalam merawat klien dirumahnya, ini disebabkan pendidikan kesehatan yang diberikan hanya menggunakan metode ceramah saja, maka peneliti tertarik untuk meneliti tentang metode pendidikan kesehatan jiwa menggunakan metode video dalam meningkatkan pengetahuan caregiver mengenai cara merawat klien halusinasi di wilayah kerja Puskesmas Jatibarang.

\section{METODE PENELITIAN}

Jenis penelitian ini merupakan penelitian kuantitatif quasi eksperimen dengan rancangan one group pretest-posttest design. Rancangan penelitian ini melibatkan satu kelompok responden (30 orang). Pemilihan responden dilakukan secara acak sebelum dilakukan intervensi, dengan sistem pengundian atau kocokan nama responden

\section{HASIL PENELITIAN}

\section{Data Umum}

Tabel 1 Karakteristik Responden

\begin{tabular}{llcc}
\hline No & Data Umum & F & \% \\
\hline & Jenis Kelamin & & \\
1 & Laki-laki & 13 & 43,3 \\
2 & Perempuan & 17 & 56,7
\end{tabular}




\begin{tabular}{|c|c|c|c|}
\hline & Usia & & \\
\hline 1 & Dewasa awal (18-44) & 6 & 20 \\
\hline 2 & Dewasa Madya (45-59) & 17 & 56,7 \\
\hline \multirow[t]{2}{*}{3} & Lansia (60-74) & 7 & 23,3 \\
\hline & Pendidikan & & \\
\hline 1 & Tidak Sekolah & 6 & 20 \\
\hline 2 & SD/sederajat & 5 & 16,7 \\
\hline 3 & SMP/sederajat & 5 & 16,7 \\
\hline 4 & SMA/sederajat & 12 & 40 \\
\hline \multirow[t]{2}{*}{5} & PT/sederajat & 2 & 6,7 \\
\hline & Status Hubungan & & \\
\hline 1 & Ibu & 12 & 40 \\
\hline 2 & Ayah & 8 & 26,7 \\
\hline 3 & Saudara Sekandung & 8 & 26,7 \\
\hline \multirow[t]{2}{*}{4} & Saudara bukan sekandung & 2 & 6,7 \\
\hline & Status Pekerjaan & & \\
\hline 1 & Bekerja & 18 & 60 \\
\hline \multirow[t]{2}{*}{2} & Tidak Bekerja & 12 & 40 \\
\hline & Lama Merawat Klien & & \\
\hline 1 & $<1$ Tahun & 3 & 10 \\
\hline 2 & $1-3$ Tahun & 5 & 16,7 \\
\hline 3 & $>3$ Tahun & 22 & 73,3 \\
\hline \multicolumn{2}{|c|}{ Total } & 30 & 100 \\
\hline \multicolumn{4}{|c|}{$\begin{array}{l}\text { Berdasarkan tabel diatas diketahui } \\
\text { sebagian besar responden perempuan } \\
\text { sebanyak } 17 \text { orang }(56 \%) \text {, sedangkan usia } \\
\text { responden dominan Pertengahan (45-59 thn) } \\
\text { sebanyak } 17 \text { orang }(56,7 \%) \text {. Pendidikan } \\
\text { responden dominan SMA/sederajat sebanyak } \\
12 \text { orang }(40 \%) \text {. }\end{array}$} \\
\hline
\end{tabular}

2. Data Khusus

\begin{tabular}{|c|c|c|c|c|}
\hline Tabel 2 Hasi & & & \\
\hline Care & iver & Intara & Sebe & um Dan \\
\hline Setel & & iberikan & & Intervensi \\
\hline \multicolumn{5}{|c|}{ Menggunakan Metode Video } \\
\hline Kelompok & Mean & $S D$ & $\mathbf{N}$ & $\begin{array}{c}\text { Nilai } P \\
\text { value }\end{array}$ \\
\hline $\begin{array}{c}\text { Pre test } \\
(0-12)\end{array}$ & 7.57 & 1.357 & 30 & \multirow{2}{*}{0,000} \\
\hline $\begin{array}{c}\text { Post test } \\
(0-12)\end{array}$ & 11.80 & 0.407 & 30 & \\
\hline
\end{tabular}

Berdasarkan tabel di atas di ketahui

bahwa rata-rata pengetahuan pre test caregiver adalah 7,57 naik menjadi 11,80 setelah dilakukan post test. Hasil analisis menggunakan uji wilcoxon didapatkan nilai Pvalue $0,000<0,05$, artinya ada perbedaan signifikan antara pengetahuan pre test caregiver dengan pengetahuan post test caregiver. Hal ini menunjukkan bahwa metode video memiliki efektifitas dalam meningkatkan pengetahuan caregiver dalam merawat klien halusinasi.

\section{PEMBAHASAN}

Penelitian ini dilakukan pada 30 orang caregiver dari klien yang memiliki halusinasi di rumahnya dan bersedia dilibatkan dalam penelitian pemberian pendidikan kesehatan dengan menggunakan metode video. Sebelum diberikan pendidikan kesehatan menggunakan video, banyak caregiver yang mempunyai pengetahuan kurang setelah diberikan pendidikan kesehatan menggunakan video pengetahuan caregiver meningkat menjadi berpengetahuan baik. Hal ini karena video yang digunakan dalam penyampaian materi pendidikan kesehatan jiwa mampu menarik perhatian para caregiver. Notoadmodjo (2012) menerangkan bahwa dalam proses pendidikan kesehatan selain dipengaruhi oleh bahan ajar dan fasilitas belajar, penggunaan metode dan alat bantu pendidikan kesehatan akan mempengaruhi hasil yang diinginkan pengajar. Pelaksanaan pendidikan kesehatan dengan metode pemutaran video yang lebih efektif dapat dikarenakan metode video mempunyai kelebihan dapat menampilkan suatu objek atau peristiwa seperti keadaan sebenarnya. Video meningkatkan retensi memori karena lebih menarik dan mudah diingat (Sardiman, 2012).

Muhdhar (2012) menyebutkan dalam penelitiannya bahwa pemberian pendidikan kesehatan dengan video dapat meningkatkan pemahaman responden. Sejalan dengan penelitian Rani (2013) penelitiannya menggunakan media video didapatkan peningkatan terhadap pengetahuan setelah dilakukan pendidikan kesehatan. Kedua penelitian ini menerangkan bahwa pendidikan kesehatan dengan metode video akan meningkatkan pengetahuan caregiver.

Metode pemutaran video dapat membentuk pengetahuan, sikap dan perilaku peserta didik dari hasil penangkapan panca indera oleh peserta didik. Seperti halnya yang dijelaskan oleh Maulana (2009), menyebutkan bahwa keberhasilan pendidikan kesehatan 
dalam merubah perilaku dipengaruhi pula oleh penangkapan panca indra. Panca indra yang paling banyak menyalurkan pengetahuan ke otak adalah mata (kurang lebih $75 \%$ sampai $87 \%$ ), sedangkan $13 \%$ sampai $25 \%$ pengetahuan diperoleh atau disalurkan melalui indera yang lain.

Efektifitas pendidikan kesehatan jiwa menggunakan video lebih efektif, dikarenakan caregiver dapat melihat langkah secara langsung yang diperagakan oleh model melalui video, dapat menarik perhatian caregiver untuk tetap fokus, materinya, sehingga caregiver tidak akan merasa bosan dan kehilangan konsentrasinya. Pendidikan kesehatan menggunakan media video pada responden tidak hanya mengandalkan indera pendengaran, namun indera pengelihatan juga sangat berperan penting untuk membantu mengingat materi yang disampaikan. Hasil penelitian ini sejalan dengan penelitian Purnama (2013) menyebutkan bahwa media video efektif dalam meningkatkan pengetahuan siswa tentang bahaya NAPZA di SMP Negeri 3 Mojosongo Boyolali.

Hal tersebut menunjukkan bahwa pada dasarnya metode video yang digunakan memiliki efektifitas dalam merubah pengetahuan caregiver merawat klien halusinasi di rumah. Sesuai dengan tujuan pendidikan kesehatan, pada dasarnya menyangkut tiga hal, yaitu peningkatan pengetahuan (knowledge), perubahan sikap (attitude), dan ketrampilan atau tingkah laku (practice), yang berhubungan dengan masalah kesehatan jiwa di masyarakat (Notoatmodjo, 2012).

\section{KESIMPULAN dan SARAN}

\section{Kesimpulan}

Penelitian ini bertujuan untuk mengetahui efektifitas pendidikan kesehatan jiwa dengan menggunakan video. Sampel yang mengikuti penelitian ini yaitu 30 orang. Simpulan penelitian yang di dapat adalah metode video efektif dalam meningkatkan pengetahuan caregiver tentang halusinasi pada pemberian pendidikan kesehatan jiwa.

\section{Saran}

1) Hendaknya Puskesmas sebagai pelaksana pelayanan kesehatan primer yang langsung berhubungan dengan masyarakat, dapat bekerjasama dengan institusi pendidikan keperawatan untuk mengadakan pelatihan kepada tenaga kesehatan atau perawat yang memegang program jiwa di puskesmasnya tentang pemberian pendidikan kesehatan jiwa menggunakan metode video sebagai dasar untuk meningkatkan kemampuan dalam memberikan pendidikan kesehatan yang lebih komprehensif dengan melibatkan caregiver atau keluarga yang mempunyai klien halusinasi.

2) Pendidikan kesehatan jiwa dengan menggunakan metode video dapat diterapkan di tatanan keperawatan jiwa khususnya keperawatan jiwa komunitas. Puskesmas sebagai tatanan pelayanan kesehatan primer dapat mengaplikasikan Pendidikan kesehatan jiwa dengan menggunakan metode video atau memberikan video cara merawat klien halusinasi melalui program kunjungan rumah (home visit) kepada caregiver atau keluarga yang memiliki klien halusinasi di rumahnya .

3) Berdasarkan hasil penelitian diatas dapat dilanjutkan penelitian mengenai faktorfaktor yang mempengaruhi peningkatan pengetahuan caregiver dalam merawat klien halusinasi di rumahnya. Penelitian juga dapat dilanjutkan dengan penelitian mengenai sikap dan perilaku keluarga dalam perawatan halusinasi.

\section{DAFTAR PUSTAKA}

Abiodun. 2014. "Impact of health education intervention on knowledge and perception of cervical cancer and cervical screening uptake among adult women in rural communities in Nigeria". Melalui http://bmcpublichealth.biomedcentral. com/articles/10.1186/1471-2458-14814.html(15/9/14).

Arsyad, A. 2007. Media Pembelajaran. Jakarta : Raja Grafindo Persada. 
Awad, A. G., \& Voruganti, L. N. 2008. The Burden of Schizophrenia on Caregivers. Journal of Pharmacoeconomics $26: 149-162$.

Dinkes Kabupaten Indramayu. 2014. Rekap Data Kasus Gangguan Jiwa Di Indramayu. Tidak dipublikasikan.

Farkhah. 2017. "Faktor Caregiver dan Kekambuhan Klien Skizofrenia". Jurnal Majalah Keperawatan Volume 5 Nomor 1.

Jaste \& Mueser. 2008. Clinical Handbook of Skizophrenia. The Guildford Press. New York. London.

Jusuf, L,. 2014. Asesmen kebutuhan caregiver skizofrenia. Melalui http://repository.ui.ac.id/contents/kole ksi/16/920649bce7abf0078ce040c079 85ec537db81c67.pdf.html(20/11/14).

Kartikasari. 2017. "Pengaruh Terapi Psikoedukasi Keluarga terhadap Self Efficacy Keluarga dan Sosial Okupasi Klien Schizophrenia". Jurnal Majalah Keperawatan Volume 5 Nomor 2 Agustus 2017.

Keliat, B, A,. 2002. Managemen Keperawatan Psikososial \& Kader Kesehatan Jiwa CMHN (Intermediate Course). Jakarta : EGC.

Kementrian Kesehatan RI. 2016. Profil Kesehatan Indonesia 2015. Jakarta : Kementrian Kesehatan RI.

Maramis, Albert. 2014. Skizofrenia dan Pentingnya Layanan Kesehatan Jiwa. Melalui http://www.tempokini.com/2014/10/s kizofrenia-dan-pentingnya-layanankesehatan-jiwa/.html(9/4/17).

Maulana. 2009. Manajemen Sumber Daya Manusia. Jakarta: Salemba Empat.

Mboi. 2016. Riset Kesehatan Dasar : Riskesdas 2013. Melalui http://www.depkes.go.id/resources/do
wnload/general/Hasil\%20

Riskesdas\%202013.pdf.html(5/4/16).

Metkono. 2014. "Hubungan Tingkat Pengetahuan dan Beban Caregiver dengan Perilaku Caregiver Dalam Merawat Pasien Relaps Skizofrenia Di Poliklinik Psikiatri Rumah Sakit Dr. H. Marzoeki Mahdi Bogor 2014". Melalui $\quad$ http://ejournal.stik$\underline{\text { sintcarolus.ac.id/file.php?file }=\text { mahasi }}$ swa

$\& \mathrm{id}=495 \& \mathrm{~cd}=0 \mathrm{~b} 2173 \mathrm{ff} 6 \mathrm{ad} 6 \mathrm{a} 6 \mathrm{fb} 09 \mathrm{c} 9$ 5f6d50001df6\&name $=$ ARTIKEL $\% 20$ ILMIAH\%20NOVIA\%20BRIGITA \%20SARI\%20METKONO.pdf.html( $8 / 10 / 14)$

Muhdhar. 2012. Penerapan DVD 6M Pendidikan Kepada Masyarakat Dalam Pengelolaan Sampah Rumah Tangga. Jurnal FKIP UNS.

Notoatmodjo. 2012. Pendidikan dan Perilaku Kesehatan. Jakarta: Rineka Cipta.

Purnama, A. P. (2013). "Efektifitas Penggunaan Media Video dan Media Leaflet terhadap Perubahan Pengetahuan dan Sikap Siswa tentang Bahaya NAPZA di SMPN 3 Mojosongo Boyolali”. Melalui http://eprints.ums.ac.id/27215/.html(1 2/8/17).

Rani, P. 2013. Effect Of Video-Assisted Teaching On Knowledge Of Family Welfare Measure Among Primigravidae In Kanyakumari Distrik. The Author Is Lecture, Obstetrics \& Gynecological Nursing, Doctors College Of Nursing, Pudukkottai (TN), NJI-OCT.

Riset Kesehatan Dasar (Riskesdas). 2013. Badan Penelitian dan Pengembangan Kesehatan Kementerian RI tahun 2013. Diakses: 29 September 2017, dari http://www.depkes.go.id

Sardiman, A.M. 2012. Interaksi dan Motivasi Belajar Mengajar. Jakarta: PT Raja Grafido Perkasa. 
Stuart \& Laraia. 2005. Principles and practice of psychiatric nursing. Elsevier Mosby. Alih Bahasa Budi Santosa. Philadelphia.

Stuart, G.,W. 2016. Keperawatan Kesehatan Jiwa. Indonesia : Elsever.

Sunaryo. 2004. Psikologi Untuk Keperawatan. Jakarta : EGC.

Suryani. 2013. "Setiap Tahun Penderita Gangguan Jiwa di Indonesia Terus Meningkat". Melalui

http://www.unpad.ac.id/profil/drsuryani-skp-mhsc-setiap-tahunpenderita-gangguan-jiwa-diindonesia-terusmeningkat/.html(10/4/16).

Sulistiowati. 2010. "Pengaruh Acceptance and Commitment Therapy Terhadap Gejala dan Kemampuan Klien dengan Resiko Perilaku Kekerasan”. Jurnal Keperawatan Jiwa Persatuan Perawat Nasional Indonesia (PPNI) Vol. 2 Nomor 1. Melalui https://repositori.unud.ac.id/protected/ storage/upload/repositori/04b3d60172 08b1fae157ea7e8fdc8ef1.pdf.html $(25 / 9 / 16)$.

World Health Organization. 2016. Mental disorders fact sheets. World Health Organization.

http://www.who.int/mediacentre/fac tsheets/fs396/en/ -Diakses Januari 2017 